\title{
Desenvolvimento de Aplicativo para Ensino de Biologia Celular e Histologia no Âmbito Universitário através de Dispositivos Móveis
}

\author{
Adilmar C. Dantas ${ }^{1}$, João G. Borges ${ }^{1}$, Pedro A. Oliveira ${ }^{2}$, Alessandra A. Satokata ${ }^{2}$, \\ Marcelo Z. do Nascimento ${ }^{1}$, Paulo R. Faria ${ }^{2}$ \\ ${ }^{1}$ FACOM - Faculdade de Ciência da Computação \\ Universidade Federal de Uberlândia \\ Av. João Naves de Ávila, 2121-38408-100 Uberlândia, MG, Brasil \\ ${ }^{2}$ ICBIM - Instituto de Ciências Biomédica \\ Universidade Federal de Uberlândia \\ Av. Pará 1720 - Bloco 2B - Sala 2B221, Uberlândia, MG, Brasil \\ email\{akanehar, joaomalaquiassb, pedroaaoliveira1994, alessandrasatokata, marcelo.zanchetta, \\ paulorfaria1976\}@gmail.com
}

\begin{abstract}
This work presents the CelulaP software to contribute to the teaching of cell biology and histology in higher education. The application has several interactive features, such as high-resolution microscopy images, theoretical material and questions. The main objective of the software is to provide educators with the possibility of inserting accessible technological tools with a strong potential to be explored during the teaching and learning process of these disciplines.
\end{abstract}

Resumo. Este trabalho apresenta um aplicativo CelulaP para auxiliar no ensino de Biologia e Histologia celular no ensino superior. O aplicativo conta com diversos recursos interativos, como por exemplo, imagens de microscopia em alta resolução, material teórico e questões. O objetivo principal da aplicação é fornecer aos educadores a possibilidade de inserir ferramentas tecnológicas acessiveis e com forte potencial para serem exploradas durante o processo de ensino e aprendizagem dessas disciplinas.

\section{Introdução}

O rápido avanço de Tecnologias de Informação (TI) e desenvolvimento de aplicações para dispositivos móveis têm trazido novas mudanças no aprendizado de conteúdos e disciplinas nas diversas áreas do conhecimento [Küçük et al. 2016]. Nos últimos anos, com o advento de dispositivos móveis (tablets, smartphones e iPods) e a ampliação ao acesso à internet no mundo e no Brasil, estudiosos têm observado o poder deles na melhoria do processo de ensino e aprendizagem [Gon and Rawekar 2017]. Desde 2011, o Horizon Report tem enfatizado a importância dos dispositivos móveis, juntamente com a computação em nuvem, nas mudanças de paradigmas educacionais. Além disso, destaca-se nesse relatório que essas ferramentas tecnológicas continuarão a ter um grande impacto nas abordagens de ensino [Churchill et al. 2015, Mayer 2002]. Sobre isso, cabe mencionar que os dispositivos móveis oferecem um amplo espectro de ferramentas para os educadores e estudantes como vídeos, áudios, gráficos e mídias integradas [Churchill et al. 2015]. 
VII Congresso Brasileiro de Informática na Educação (CBIE 2018)

Anais do XXIX Simpósio Brasileiro de Informática na Educação (SBIE 2018)

Atualmente existem aplicativos disponíveis nos sistemas de repositório do Apple Store (Apple) e Play Store (Google) para as áreas de biologia celular e histologia. Dentre os mais utilizados são os iCell, 3DCell, Typical Animal Cell, Cell Atlas, etc, todos com divergência entre os docentes nos critérios de pontos negativos e positivos [Stark 2012]. Isso mostra que o uso desses aplicativos como ferramenta de aprendizado pelos estudantes têm se popularizado nos países desenvolvidos, onde há algum tempo vêm explorando o poder das mídias digitais na consolidação do conhecimento pelos alunos. No entanto, todo o conteúdo é concentrado na língua inglesa e muitos só permitem o acesso integral ao conteúdo desde que o usuário faça o pagamento, que muitas vezes é cobrado em moeda americana [Stark 2012], ou seja, um software de características proprietária. No Brasil, devido ao engessamento do sistema curricular em todos os níveis, esse processo tem ocorrido muito lentamente e existem várias razões para isso. Mesmo dentro das Universidades, onde o acesso à internet é fácil e gratuito, não existe indicação, por parte dos docentes de aplicativos aos seus estudantes, especialmente porque muitos deles, senão todos, estão em língua inglesa.

Assim, considerando o poder dessa ferramenta no processo de ensinoaprendizagem, a ausência de aplicativos de biologia celular e histologia disponíveis para smartphone em língua portuguesa e, mais importante, sem custo para o estudante, o presente trabalho apresenta um aplicativo para smartphone com conteúdo das disciplinas de Biologia Celular e Histologia para que os alunos possam consolidar os conhecimentos passados pelos professores em sala de aula.

\section{CelulaP: Um aplicativo para ensino de biologia celular e histologia}

O "CelulaP" é um aplicativo móvel e web que tem como objetivo facilitar o processo de ensino e aprendizagem por intermediação de tecnologias atuais. $\mathrm{O}$ aplicativo disponibiliza conteúdos didáticos sobre os assuntos de biologia celular e histologia, através da utilização de imagens de microscopia de alta qualidade e questões de múltipla escolha que permite avaliar o progresso de aprendizagem dos estudantes e realize recomendações quando necessário.

\subsection{Materiais e Métodos}

Para o desenvolvimento do aplicativo foi utilizado a linguagem HTML5 versão 5.2, uma linguagem de marcação simples e com uma grande gama de recursos computacionais para estruturar documentos para plataformas de desenvolvimento de aplicativos [Mozilla 2018]. A comunicação lógica, criação e interpretação de eventos foi realizada utilizando o jQuery Mobile, um sistema de interface baseado no HTML5, que possibilita a criação de aplicações acessíveis [jQuery 2017]. Esse recurso possibilita sua execução em qualquer dispositivo que possua um navegador web.

Como na aplicação terá atividades para que os alunos avaliem seus conhecimentos adquiridos no decorrer da utilização. Nesse projeto foi necessário o desenvolvimento de um banco de dados MySql, um sistema de gerenciamento de banco de dados que utiliza a linguagem SQL do tipo relacional, bastante popular para aplicações online [Delisle 2006]. Esse banco será responsável por armazenar informações de cada aluno, tais como: informações de acesso, progresso e desempenho.

A aplicação possuiu quatro etapas fundamentais. A primeira responsável por cadastrar o aluno no aplicativo para que seja elaborado o seu perfil de estudante contendo 
VII Congresso Brasileiro de Informática na Educação (CBIE 2018)

Anais do XXIX Simpósio Brasileiro de Informática na Educação (SBIE 2018)

suas respectivas informações de acesso e nível de progresso de aprendizagem. O segundo passo é responsável por disponibilizar os conteúdos para estudo. Já no terceiro passo são exibidos materiais teóricos sobre a determinada estrutura celulares escolhidas pelo estudante. Também há a opção de visualizar a imagem em alta resolução e suas respetivas estruturas de maneira detalhada. Finalmente, o estudante pode executar um questionário com questões sobre o assunto explorado com objetivo de avaliar o conhecimento adquirido. Os principais fluxos e interfaces que compõe o aplicativo são mostrados na Figura 1.

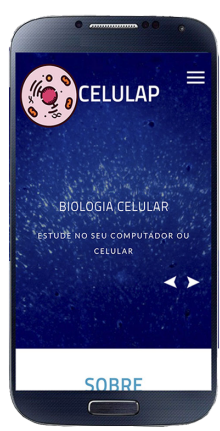

(a)

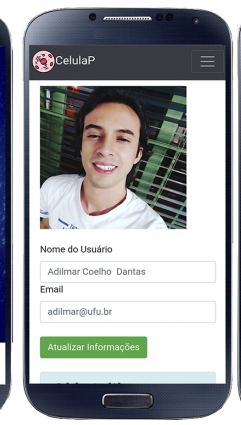

(b)

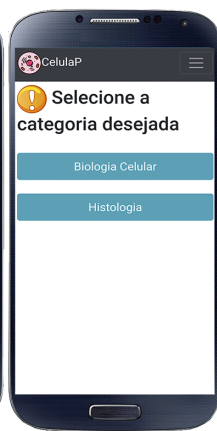

(c)

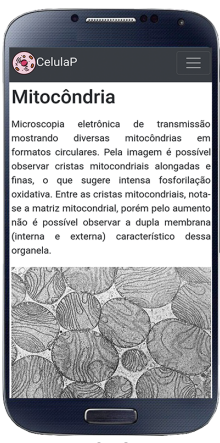

(d)

Figura 1. Interfaces funcionais do aplicativo: tela inicial (a), perfil do estudante (b), modalidade de estudo (c) e material teórico (d).

$\mathrm{Na}$ interface responsável por disponibilizar o material teórico (ver Figura 1(d)) é exibido uma imagem em alta resolução, feita através de microscópico da região explorada. Essa imagem permite que o aluno análise com uma maior riqueza os detalhes e particularidades dessa estrutura através da análise visual ou textual disponibilizadas para o usuário.

\subsection{Considerações Finais}

O uso de tecnologias como mobile learning (M-learning) é uma nova forma de aquisição de conhecimento, o qual foca no ensino através de textos e imagens em dispositivos móveis. Isso poderá proporcionar flexibilidade ao processo de aprendizagem e oferecem grandes oportunidades para educação, especialmente para os mais jovens. Assim, essa aplicação pode contribuir de maneira significativa para processo de ensino e aprendizagem nas universidades.

\section{Referências}

Churchill, D., Lu, J., Chiu, T. K., and Fox, B. (2015). Mobile Learning Design. Springer.

Delisle, M. (2006). Creating your MySQL Database: Practical Design Tips and Techniques. Packt Publishing Ltd.

Gon, S. and Rawekar, A. (2017). Effectivity of e-learning through whatsapp as a teaching learning tool. MVP Journal of Medical Sciences, 4(1):19-25.

jQuery (2017). Jquery mobile about@ONLINE.

Küçük, S., Kapakin, S., and Göktaş, Y. (2016). Learning anatomy via mobile augmented reality: Effects on achievement and cognitive load. Anatomical sciences education, 9(5):411-421. 
VII Congresso Brasileiro de Informática na Educação (CBIE 2018)

Anais do XXIX Simpósio Brasileiro de Informática na Educação (SBIE 2018)

Mayer, R. E. (2002). Multimedia learning. Psychology of learning and motivation, 41:85139.

Mozilla (2018).Html5@ONLINE.

Stark, L. A. (2012). Cell biology apps for apple devices. CBE-Life Sciences Education, 11(3):226-230. 